\title{
Predictive value of plasma haematocrit level in early diagnosis of pre-eclampsia
}

\author{
F. Golboni, ${ }^{1}$ S. Heydarpour, ${ }^{2}$ Z. Taghizadeh ${ }^{3}$ and A. Kazemnezhad ${ }^{4}$
}

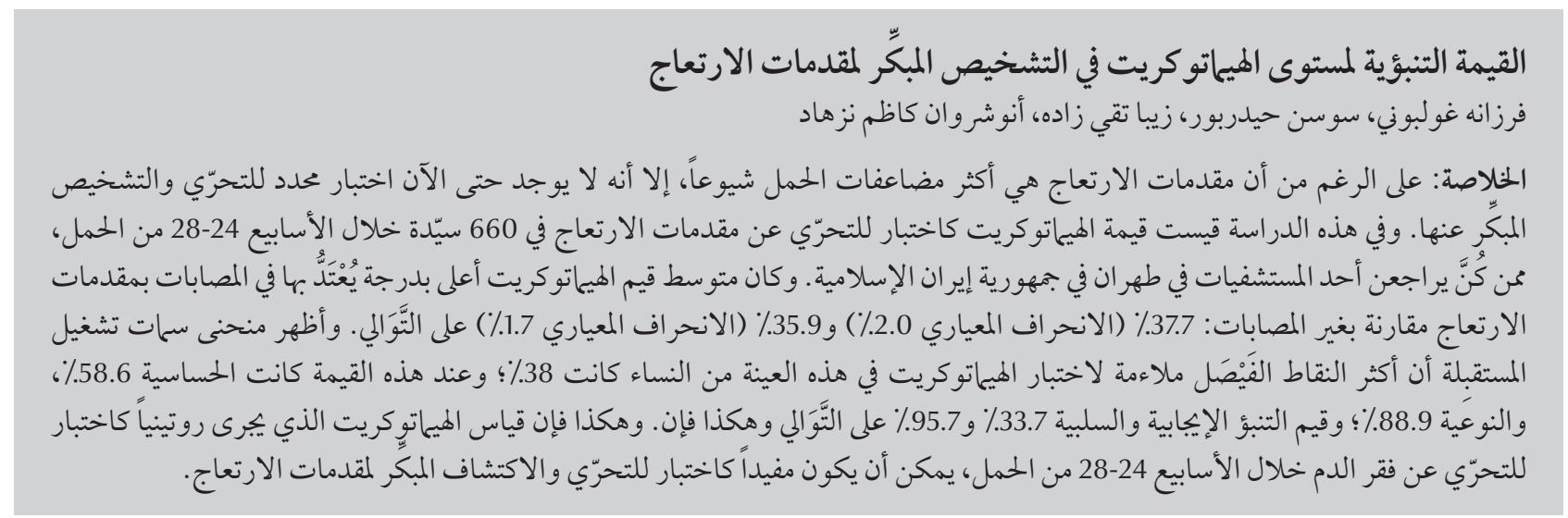

ABSTRACT While pre-eclampsia is the most common complication of pregnancy, a definitive screening test for early diagnosis is still elusive. In this study, haematocrit value was assessed as a screening test for pre-eclampsia in 660 women at 24-28 weeks of pregnancy attending a hospital in Tehran, Islamic Republic of Iran. Mean haematocrit values were significantly higher in pre-eclamptic than non-pre-eclamptic women: 37.7\% (SD 2.0\%) and 35.9\% (SD 1.7\%) respectively. The receiver operating characteristics curve showed that the most appropriate cut-off point for the haematocrit test in this sample of women was 38\%; at this value the sensitivity was $58.6 \%$ and specificity was $88.9 \%$; positive and negative predictive values were $33.7 \%$ and $95.7 \%$ respectively The haematocrit, done as a routine screening test for anaemia at 24-28 weeks of pregnancy, may also be useful as a screening test for early diagnosis of pre-eclampsia.

\section{Valeur prédictive du taux d'hématocrite plasmatique pour le diagnostic précoce de prééclampsie}

RÉSUMÉ Si la prééclampsie est la complication la plus fréquente pendant une grossesse, un test de dépistage définitif pour un diagnostic précoce est encore difficile à réaliser. Dans la présente étude, le taux d'hématocrite a été évalué en tant que test de dépistage de la prééclampsie chez 660 femmes enceintes de 24 à 28 semaines consultant dans un hôpital de Téhéran (République islamique d'Iran). Les taux d'hématocrite moyens étaient significativement supérieurs chez les femmes atteintes de prééclampsie par rapport aux autres femmes: 37,7 \% (E.T. 2,0 \%) et 35,9\% (E.T. 1,7\%) respectivement. La courbe de la fonction d'efficacité du récepteur a révélé que la valeur seuil la plus appropriée pour l'analyse du taux d'hématocrite dans cet échantillon de femmes était $38 \%$; à cette valeur seuil, la sensibilité était de 58,6 \% et la spécificité de 88,9\% ; les valeurs prédictives positives et négatives étaient de 33,7 \% et de 95,7 \% respectivement. L'analyse du taux d’hématocrite, réalisée en dépistage systématique de l'anémie entre la vingt-quatrième et la vingt-huitième semaine de grossesse, peut également être utile en tant que test de dépistage permettant l'établissement d'un diagnostic précoce de prééclampsie.

${ }^{1}$ Department of Nursing Midwifery, Azad University, Sanandaj, Islamic Republic of Iran.

${ }^{2}$ Department of Nursing Midwifery, Kermanshah University of Medical Sciences, Kermanshah, Islamic Republic of Iran (Correspondence to S.

Heydarpour:susan_haidarpor@yahoo.com).

${ }^{3}$ Department of Nursing Midwifery, Tehran University of Medical Sciences, Tehran, Islamic Republic of Iran.

${ }^{4}$ Department of Biostatistics, Tarbiat Modares University, Tehran, Islamic Republic of Iran.

Received: 10/08/09; accepted: 10/03/10 


\section{Introduction}

Pre-eclampsia is the most common complication of pregnancy and, together with bleeding and infection, is one of the 3 main causes of death in mothers. It has been notified as a global health problem of women by the World Health Organization (WHO) $[1,2]$. Pre-eclampsia is a pregnancy-specific syndrome of unknown aetiology and diagnosed by systolic blood pressure $\geq 140 \mathrm{mmHg}$ and/or diastolic blood pressure $\geq 90 \mathrm{mmHg}$ and proteinuria $\geq 300 \mathrm{mg} / 24 \mathrm{~h}$ or dipstick 1-plus after 20 weeks of pregnancy. Despite proper care during pregnancy and delivery, preeclampsia is still a major health threat, even in developed countries $[3,4]$.

The prevalence of this disease in the world has been estimated at $5 \%-7 \%$ and in the Islamic Republic of Iran in Tehran at $6.5 \%$ [4-6]. A reliable criterion for early diagnosis of pre-eclampsia does not exist. Many clinical, biophysical and biochemical tests exist for the diagnosis of high-risk women, but the results of studies indicate they had little predictive value in early diagnosis. Furthermore, some of these screening tests are expensive and invasive $[3,6-8]$. Some research has indicated that haemodynamic changes in normal pregnancy, such as the increase of maternal plasma volume in the second trimester, do not occur in pre-eclampsia. This may, therefore, be an indicator for pre-eclampsia in future weeks $[1,3,4,9,10]$. Due to vasospasm and absence of hypervolumia in these patients the haematocrit value may increase $[1,9,11]$. In some studies serum haematocrit has been reported as an early diagnostic test for pre-eclampsia $[1,10,12]$.

This study aimed to determine the predictive value of maternal haematocrit value at 24-28 weeks of pregnancy in the early diagnosis of pre-eclampsia. Maternal haematocrit is measured routinely in our hospital in the Islamic Republic of Iran for the diagnosis of anaemia at this stage of pregnancy and if the predictive value of this test is appropriate it may be recommended as a screening test for pre-eclampsia.

\section{Methods}

\section{Sample}

Sampling and follow-up of cases took 8 months from February 2006 to September 2007. The sample was selected from pregnant women attending the prenatal care clinic at Maryam hospital in Tehran, Islamic Republic of Iran. Women with underlying diabetes, chronic hypertension, symptomatic infectious disease, renal disease, pulmonary disease, rheumatologic disease or thyroid disease were excluded from the study. Women with multiple pregnancies, antiphospholipid syndrome, anaemia, polycythaemia, body mass index (BMI) $\geq 30 \mathrm{~kg} / \mathrm{m}^{2}$ and history of recurrent pregnancy loss were also excluded.

The sample size was estimated with a $95 \%$ level of significance and $P<0.05$ and assuming a positive predictive value of the test of $30 \%-40 \%$, as reported in various studies. Thus 323 cases were estimated to be required. Taking into account possible losses, sample size was increased to 330 per category ( 330 women with 24-26 weeks gestational age and 330 with $27-28$ weeks gestational age). Thus over the study period 660 pregnant women with a fetus at gestational age 24-28 weeks were enrolled. All gave informed consent for participation in the study. Three months after starting the sampling 52 women dropped out because of non-attendance at the clinic or refusal to participate and resampling was continued until the sample of 660 was completed. All women were taking regular ferrous sulfate supplements. Gestational age was estimated from the last menstrual period and confirmed by sonography in the first trimester of pregnancy.

\section{Data collection}

All the women were interviewed to record demographic data (age, marital status education, employment) and information about number of pregnancies, history of labour, history of abortion, history of pre-eclampsia and BMI in the first trimester of pregnancy.

Blood pressure was measured using a stethoscope and sphygmomanometer. Pre-eclampsia was defined as blood pressure of $140 / 90 \mathrm{mmHg}$ or greater obtained on 2 consecutive measurements $6 \mathrm{~h}$ apart, with proteinuria $\geq+1$ on 2 random urine samples or urine total protein $>300 \mathrm{mg}$ in $24 \mathrm{~h}$. All measurements were done on one of 2 identical sphygmomanometers, whose accuracy was determined by the medical engineer of Maryam hospital.

Blood and urine samples were taken for routine screening tests. Haematocrit was measured once in each woman by centrifugation (Sysmex). The reliability of the centrifuge was checked by calibration daily in the hospital laboratory. Other tests, including measurements of platelet count, prothrombin time, partial thromboplastin time, serum urate and diagnostic parameters of liver and kidney function, were done to diagnose pre-eclampsia.

All women were followed-up for the remainder of their pregnancy for the occurrence of pre-eclampsia.

\section{Analysis}

For classifying and summarizing data, descriptive statistics were used. For the comparison of haematocrit results at 24-28 weeks in women with and without pre-eclampsia, the chi-squared test was used. The sensitivity and specificity of the haematocrit test were assessed using standard equations. For determining an appropriate cut-off point for the test, a receiver operating characteristic (ROC) curve was used. SPSS software, version 15 , was used for analysis. $P$-values $<0.05$ were considered significant.

\section{Results}

The majority (91.7\%) of the subjects were aged $19-35$ years old. Their 
mean age was 25.7 (SD 4.9) years. Most women (66.7\%) had secondary education, $98.5 \%$ were married once and $91.5 \%$ were housewives. Pregnancy history showed that $462(70.0 \%)$ of women were primigravidas, $73.9 \%$ had no history of delivery and $93.3 \%$ had no history of abortion. In the 198 multigravidas, $93.4 \%$ had no a history of pre-eclampsia in previous pregnancies. BMI was normal (19.8-26 kg/ $\mathrm{m}^{2}$ ) in two-thirds (65.5\%) of the women.

Of the 660 pregnant women, $58(8.8 \%)$ had a diagnosis of preeclampsia and 602 had no signs of pre-eclampsia. The mean haematocrit values were significantly higher in pre-eclamptic than non-pre-eclamptic women: $37.7 \%$ (SD 2.0\%) and $35.9 \%$ (SD 1.7\%) respectively (chi-squared $P<0.001$ ).

The ROC curve of sensitivity and specificity of the test showed that the optimal cut-off point for the haematocrit test in this sample of women at 24-28 weeks of pregnancy was 38\% (Figure 1). Using this haematocrit cut-off $65.8 \%$ of women with a diagnosis of preeclampsia had a haematocrit above the cut-off compared with $11.1 \%$ of women without pre-eclampsia (Table 1). Thedifferencebetween the 2 groups was statistically significance $\left(\chi^{2}=92.05, P<0.001\right)$. The sensitivity of the test using the $38 \%$ cut-off was $58.6 \%$ and specificity was $88.9 \%$ (Table 1). Positive predictive value was $33.7 \%$ and negative predictive value of the test was $95.7 \%$.

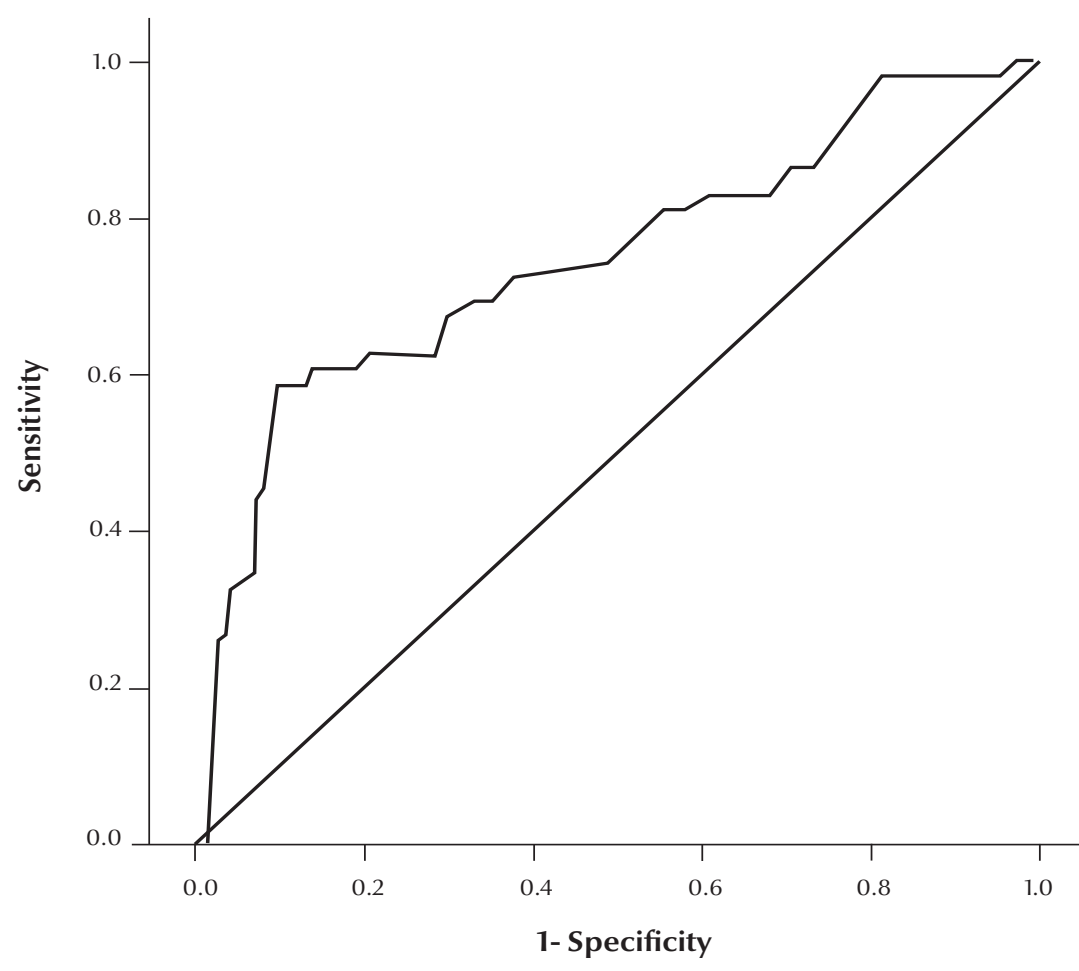

Figure 1 Receiver operating characteristics curve showing optimal cut-off point for haematocrit value in early diagnosis of pre-eclampsia in women at 24-28 weeks of pregnancy

\section{Discussion}

The pathogenesis of pre-eclampsia has not been well understood. In fact, the phenomenon may be silent from some time (2-3 months) before hypertension is expressed and the diagnosis of pre-eclampsia can be made [13]. Some evidences suggests that plasma volume in pre-eclampsia is lower than normal. Decreased plasma volume induces high haemoglobin concentration that leads to decreased placenta circulation that plays a pathogenic role in the development of pre-eclampsia [14].

Mello et al. assessed biochemical patterns in the early diagnosis of preeclampsia. They showed that the sensitivity of the haematocrit test in early diagnosis of pre-eclampsia was 63\% and its specificity was $90 \%$. Its positive predictive value was 36\% and the negative predictive value of the test was $92 \%$ [15]. Their results are in accordance with ours. In Mello's research, the haematocrit was measured every 4 weeks from the 8th week of pregnancy and the results were compared between the

\begin{tabular}{|c|c|c|c|c|c|c|}
\hline \multirow[t]{3}{*}{ Haematocrit (\%) } & \multirow[t]{3}{*}{ Total } & \multicolumn{4}{|c|}{ Pre-eclampsia } & \multirow[t]{3}{*}{ Statistics } \\
\hline & & \multicolumn{2}{|c|}{ Yes } & \multicolumn{2}{|c|}{ No } & \\
\hline & & No. & $\%$ & No. & $\%$ & \\
\hline$\geq 38$ & 101 & 34 & 65.8 & 67 & 11.1 & \\
\hline$<38$ & 559 & 24 & 44.1 & 535 & 98.8 & $\chi^{2}=92.05, P<0.001$ \\
\hline Total & 660 & 58 & 100.0 & 602 & 100.0 & \\
\hline
\end{tabular}


2nd and 3rd trimesters. Mello's methods were different from ours because we measured the haematocrit only at 24-28 weeks of pregnancy. Our results showed that it may be possible to get the same predictive value by measuring haematocrit only once.

Our results are also in accordance with those of Hilmann et al., who assessed the relationship between haemoglobin and haematocrit value in pregnancy outcome. The results of that cohort study showed that high haemoglobin and haematocrit values in the 2nd trimester have a relationship with pre-eclampsia in the following weeks [16]. They studied the relationship between haemoglobin and haematocrit value with high blood pressure in pregnancy, including transient hypertension, pre-eclampsia, eclampsia and pre-eclampsia superimposed on chronic hypertension. We only investigated the relationship between haematocrit and pre-eclampsia.

In the Islamic Republic of Iran Goudarzi et al. found a statistically significant relationship between the haematocrit value in the 1st and 3rd trimester and development of pre-eclampsia [14]. Another study in our country showed that the haematocrit value was significantly higher in pre-eclamptic women [17]. Other studies in other countries also found a relationship between an increased haematocrit and pre-eclampsia [18-21]. Other studies have shown varying results, however. In Sibai's study the haematocrit was reported as only a weak test for the diagnosis of preeclampsia. The sensitivity of the haematocrit in early diagnosis of pre-eclampsia in their study was $20 \%$, specificity was $42 \%$, positive predictive value was $6 \%$ and negative predictive value was $50 \%$ [22]. In complete contrast, Sherbiny et al. reported no significant difference in haemoglobin concentration and haematocrit value between pregnant women with pre-eclampsia (mild and severe pre-eclampsia) and a normotensive matched control group [23].

\section{Conclusion}

Haematocrit, which is routinely done as a screening test for anaemia in 24-28 weeks of pregnancy, may be useful as a screening test for early diagnosis of preeclampsia in health centres. Women with haematocrit above the cut-off of $38 \%$ should be monitored carefully for the signs of pre-eclampsia.

\section{References}

1. Heilmann L, Rath W, Pollow K. Hemorheological changes in women with severe Pre-eclampsia. American Journal of Obstetrics and Gynecology, 2004, 31:49-58.

2. Douglas KA, Redman CW. Eclampsia in the United Kingdom. British Medical Journal, 1994, 309:1395-1400.

3. Lund CJ, Donovan JC. Blood volume during pregnancy.significance of plasma and red cell volumes. American Journal of Obstetrics and Gynecology, 1967, 98:394-403.

4. Friedman SA, Lindheimer MD. Prediction and differential diagnosis. In: Lindheimer MD, Roberts JM, Cunningham FG, eds. Chesley's hypertensive disorders in pregnancy, 2nd ed. New York, Appleton and Lange, 1999:201.

5. Fayyad AM, Harrington KF, Kevin FH. Prediction and prevention of pre-eclampsia and IUGR. Early Human Development, 2005, 81:865-876.

6. Hasani MR. [Relationship between hemoglobin and hematocrit value in pregnancy outcome]. Medical School of Shahed University Journal, 2001, 20:18-26 [in Farsi].

7. Lain KY, Roberts JM. Contemporary concepts of the pathogenesis and management of pre-eclampsia. Journal of the American Medical Association, 2002, 287:3183-3186.

8. Dekker GA, Sibai BM. Early detection of pre-eclampsia. American Journal of Obstetrics and Gynecology, 1991, 165:160-172.

9. Hatfield A, Robinson E. The "debriefing" of clients following the birth of a baby. The Practising Midwife, 2002, 5(5):14-16.

10. Lindheimer MD et al. Chesley's hypertensive disorders in pregnancy, 2nd ed. New York, Appleton and Lange, 1999.

11. Walker JJ. Pre-eclampsia. Lancet, 2000, 356:1260-1265.

12. Gabbe SG et al. Obstetrics: normal and problem pregnancies, 4th ed. Edinburgh, Churchill Livingstone, 2002:315-317.

13. Taheripanah R, Bustani Farkush P. Relation between serum ferritin and iron parameters with pre-eclampsia. Journal of Family and Reproductive Health, 2007, 1:87-91.
14. Goudarzi M, Yazdin-Nik A, Bashardoost N. [The relationship of the first/ third trimester hematocrit level with the birth weight and pre-eclampsia]. Iran Journal of Nursing, 2008, 21:41-49 [in Farsi].

15. Mello G et al. Individual longitudinal patterns in biochemical and hematological markers for the early prediction of preeclampsia. Journal of Maternal-Fetal and Neonatal Medicine, 2002, 11:93-99.

16. Heilmann L, Hojnacki B, Spanuth E. Hamostase und Praeklampsie. [Hemostasis and pre-eclampsia.] Geburtshilfe und Frauenheilkunde, 1991, 51:223-227.

17. Ensafgo M. [Relationship between hemogolobin and hematocrit with outcome of pregnancy in pregnant women reffering to Shariati hospital]. [MSc thesis]. Department of Obstetrics and Gynaecology. Tehran, Medical Sciences Faculty, Tehran University of Medical Sciences, 1998 [in Farsi].

18. MurphyJF et al. Relation of haemoglobin levels in first and second trimesters to outcome of pregnancy. Lancet, 1986,1:992995.

19. Stove S, Diko L, Ivanov S. Khemoreologichni parametri v prognozata na riska ot retardatsiia na ploda pri bremennost $s$ arterialna khipertoniia [Hemorheological parameters in the prognosis of the risk of fetal retardation in pregnancy with arterial hypertension]. Akusherstvo i Ginekologiia, 1996, 35:23-24.

20. Huisman A, Aarnoudse JG. Increased 2nd trimester hemoglobin concentration in pregnancies later complicated by hypertension and growth retardation; early evidence of a reduced plasma volume. Acta Obstetricia et Gynecologica Scandinavica, 1986, 65:605-608.

21. Heilmann L, Schmid-Schonbein H. Hamodynamische und hamorrheologische Befunde bei Patientinnen mit Schwangerschaftshypertonie: Vergleich zwischen Praeklampsie und chronischer Hypertonie. [Hemodynamic and hemorheologic 
findings in patients with pregnancy-induced hypertension: comparison of pre-eclampsia and chronic hypertension]. Klinische Wochenschrift, 1990, 68(11):559-564.

22. Sibai BM. Hypertention in pregnancy. In: Gabbe SG et al., eds. Obstetrics: normal and problem pregnancies, 4th ed. Edinburgh, Churchill Livingston 2002:588-590.
23. El Sherbiny W, Kamal S. Circulating microparticles in preeclampsia. Anatolian Journal of Obstetrics \& Gynecology, 2009, $4: 1$

\section{WHO recommendations for prevention and treatment of pre-eclampsia and eclampsia}

Hypertensive disorders of pregnancy are an important cause of severe morbidity, long-term disability and death among both mothers and their babies. Among the hypertensive disorders that complicate pregnancy, pre-eclampsia and eclampsia stand out as major causes of maternal and perinatal mortality and morbidity.

The majority of deaths due to pre-eclampsia and eclampsia are avoidable through the provision of timely and effective care to the women presenting with these complications. Optimizing health care to prevent and treat women with hypertensive disorders is a necessary step towards achieving the Millennium Development Goals.

WHO has developed the above-mentioned evidence-informed recommendations with a view to promoting the best possible clinical practices for the management of pre-eclampsia and eclampsia. The final recommendations were formulated and approved by an international group of experts who participated in the WHO Technical Consultation on the Prevention and Treatment of Pre-eclampsia and Eclampsia, held in Geneva, Switzerland, on 7-8 April 2011. The recommendations are available at: http:/ / www.who.int/reproductivehealth/publications/maternal_perinatal_ health/9789241548335/en/ 